\title{
O HISTORIADOR E O SAMBISTA
}

\author{
Daniel Candeias*
}

* Doutorando no Programa de Pós-Graduação em Teoria Literária e Literatura Comparada na FFLCH - USP. E-mail: delcandeias@yahoo.com.br. 


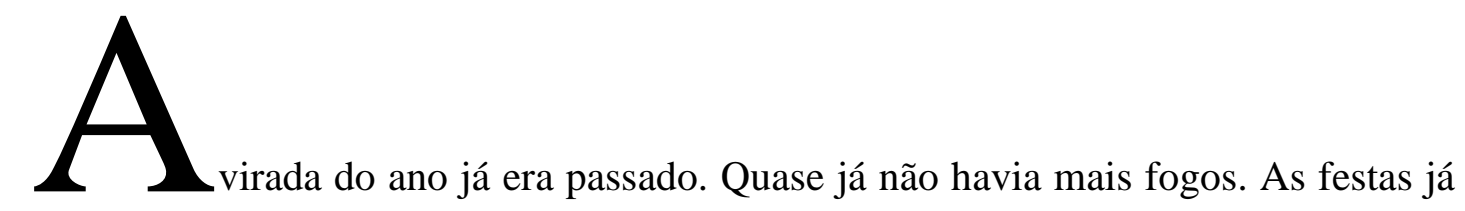
tinham morrido. As mulheres dormiam ébrias, macilentas como defuntos. As nuvens corriam negras no céu como um bando de corvos errantes. E ele vagava pelas ruas, fugindo do fim.

Ele não queria uma bebedeira. Tinha bebido bastante. Só achava que tudo passara rápido demais e procurava um lugar onde pudesse comer uns salgados e tomar mais umas duas garrafinhas para encerrar a comemoração.

Acontece que no dia primeiro de janeiro até São Paulo para de funcionar e todos os bares e padarias de última hora estavam fechados. Por isso amanhecia e nada de cerveja, nem mesmo um pão na chapa.

Ele já estava desistindo, quando finalmente deparou com uma padaria que, pela movimentação, parecia que abriria em pouco tempo. Nunca tinha reparado nela, apesar de ela se localizar num ponto bem visível de seus caminhos diários e naquele momento se deu conta de que o nome dela era "Milagrosa". Ainda atordoado pela bebedeira, sentou-se na calçada da frente e foi lendo o letreiro e balbuciando para si mesmo: "Milagrosa, padaria, você é realmente milagrosa"...

Às seis em ponto ela abriu.

Lá estavam os funcionários, evidentemente mal-humorados, assando pães e salgados, limpando o chão, organizando garrafas e talheres com a precisão e a austeridade de um militar para afugentar o desânimo e os devaneios. O bêbado ainda observava de fora, pois tinha receio de que sua entrada assim tão imediatamente após o início do expediente pressionasse e irritasse ainda mais os funcionários.

Apoiou as mãos no concreto e passou a observar os pássaros que pousavam nos fios elétricos. Batucando o chão com os pés, começou a cantar uma música sem sentido, enquanto esperava que pelo menos dois fregueses entrassem na padaria. Essa tinha sido a condição que ele havia criado para si mesmo. A não ser que isso demorasse mais de meia hora para acontecer.

Porém não demorou nem cinco minutos. Dois rapazes entraram rapidamente, se sentaram e cada um pediu sua cerveja. Ô, milagrosa! Bradou o bêbado, que levantou logo em seguida e se emparelhou com os outros dois diante do balcão. A cena era meio de piada 
mesmo, tipo "num dia primeiro de janeiro, logo depois do Réveillon, tinha um português, um alemão e um argentino bêbados num bar". Com a diferença de que, nesse caso, os três eram brasileiros, um era sambista, outro historiador e o terceiro tinha profissão desconhecida.

O historiador era aquele que chegara antes de a padaria abrir e tivera de esperar a entrada dos outros. Quando o sambista descobriu sua área de atuação, no meio de uma conversa ainda desarticulada, comentou empolgado:

- Que legal, rapaz! Mas me conta aí. Você estuda algum assunto específico?

- Nazismo.

- Nazismo?! - surpreendeu-se o sambista.

- É. Isso mesmo.

O sambista arqueou os lábios, encheu os três copos, deu uma golada e continuou:

- Caramba! Mas que assunto... Por que você estuda isso?

O historiador não podia esperar que, àquela hora, em pleno início de ano, numa padaria fuleira, uma pergunta tão agradável lhe fosse feita. Abriu um sorriso e de olhar reavivado respondeu:

- Ah, é um período muito intrigante! Primeiro, porque é inacreditável como um grupo de lunáticos, liderado pelo maior lunático de todos, conseguiu fazer a cabeça de um país de tantos pensadores importantes. Segundo, porque a Alemanha nazista talvez tenha sido o maior exemplo da habilidade que os Estados têm de manter uma imagem ideal de si e dos seus governantes. Depois que a guerra acabou, principalmente agora, quando tantos anos passaram, podemos ver como era a realidade por baixo dos panos. O que eu acho mais interessante são as pesquisas que revelam como figuras tão idealizadas também são de carne e osso e como vacilaram e fizeram seus trambiques. São muitas histórias. E eu sou historiador porque é disso que eu gosto: contar e ouvir histórias.

- Então conta uma aí - pediu o sambista.

-De nazismo? - perguntou ainda mais surpreso e feliz.

-Isso.

- Tá bom - arrumou-se no banquinho desconfortável, ajeitou um pouco o que sobrara da memória naquela noite tão dispersiva e perguntou: - Você sabia que o Hitler era rico pra caralho?

- Saber eu não sabia. Mas imaginava. Ele comandava tudo lá na Alemanha...

- Não. Antes disso.

- Como assim antes disso? 
- Mais ou menos uns dez anos antes de subir ao poder, ele participou de um movimento político muito importante no país. Como esse movimento não deu certo, foi preso, mas, por causa disso, tanto ele quanto o seu partido ficaram muito conhecidos. Quando saiu da prisão, uma parte do seu livro "Minha luta" já estava pronta. Ele a publicou e ela fez um sucesso tremendo. Aí, o dinheiro começou a entrar... Também por causa do livro, seu partido começou a crescer. Com seu crescimento, o partido recebia doações e passou a produzir um jornal que era vendido nas ruas. E como separavam as finanças do Hitler das do partido? Não separavam. Afinal, um não fazia sentido sem o outro. Imaginem quanto dinheiro o cara não ganhou nesse esquema... Não contente com isso, ainda havia empresários que se identificavam com as ideias do futuro ditador e sempre contribuíam com ele de alguma forma. Vou te dar um exemplo. O marco alemão era uma moeda bastante frágil na época. Muitas vezes as notas precisavam ser queimadas, porque já não valiam mais nada. O Führer tinha um esquema com o Henry Ford e, por isso, conseguia trocar muitos marcos por dólares, evitando o problema de desvalorização. Nesse período aí, que foi mais ou menos até o começo da década de trinta, ele ganhou tanto dinheiro que, num país em falência, andava com chofer numa Mercedes caríssima e chegou a ser apelidado de "Rei de Munique". O pior é que ele foi convocado a prestar contas ao fisco diversas vezes, pois, como tudo indica, era um grande sonegador. O seu nacional socialismo não era tão socialista assim... Agora imaginem esse sujeito com essa grana toda discursando para os trabalhadores miseráveis, tipo os da Siemens, de igual para igual, falando de um passado de pobreza que, na verdade, nem existiu, já que, quando Hitler era teoricamente pobre, seus pais financiavam seus estudos, ou seja, sua única atividade era pintar e estudar artes plásticas... Depois que ele virou chanceler em 1933, então, seu patrimônio cresceu ainda mais. Cansado de prestar contas ao fisco, ele conversou com os responsáveis pela área financeira da Alemanha, e, assim, ficou livre de impostos. Isso mesmo. Lucro da venda dos livros, lucro da venda de jornais, rendimentos do partido e nada de imposto. Daí em diante, a coisa só avançou. E, se antes não era possível separar as contas do político das do partido, agora não havia como separar as do Führer das do país. E olha que ele colocou o pessoal para trabalhar... Primeiro, nas indústrias, na construção de estradas e na revitalização de cidades. Segundo, na produção de armamentos, que vocês devem imaginar o quanto se desenvolveu para financiar invasões. Enquanto ele ia enriquecendo, alugou uma casa nos Alpes num lugar inóspito cercado por uma paisagem idílica. Com o tempo ele a comprou. E em 1936 saiu do casarão onde morava em Berlim para viver em meio à natureza. É claro que, para isso, Hitler teve que modificar o estilo tradicional da casa, adaptando-a as suas necessidades. Ele era tradicionalista, mas nem tanto assim... No final das contas, ela ficou com trinta quartos, dez quilômetros quadrados de terreno (se é que podemos chamar de 
terreno) e janelas panorâmicas gigantescas para admirar as montanhas. Tudo isso custou cem milhões de marcos... Além disso, ao redor dessa área toda foi criado um complexo que pudesse alojar todo o pessoal necessário para assessorar o Führer, dando um total de quatorze quilômetros quadrados. Um dos slogans que sua equipe de propaganda usava era "Hitler é a Alemanha e a Alemanha é Hitler", mas, enquanto a Alemanha se matava nas guerras, lá estava ele admirando os Alpes, ao lado da mulher, que era uns vinte anos mais nova.

-Cacete! Mas só tem pilantra nesse mundo! - exclamou o sambista.

- Pois é!

Apesar de comprida, a história entusiasmou o recente parceiro de bebedeira do historiador. Ele levantou os olhos, como se estivesse medindo o tamanho da loucura que acabara de ouvir, serviu a si e aos outros. Depois de pedir mais uma garrafa ao atendente, não resistiu e perguntou:

- Mas me diz uma coisa: como é que um cara desse ainda consegue uma mulher?

- Ih, você não sabe nem a metade. Eu acho que essa não era nem a maior admiradora que ele tinha.

-Cacete! Tinha mais de uma? O cara era feio que nem o diabo...

-Ô, se tinha. A maior delas foi uma filha de aristocratas ingleses.

- E era bonita?

-O pior é que não era de se jogar fora.

- Cacete. Só eu que não arranjo mulher. - deu uma boa golada e continuou: - Por que ela era a maior admiradora?

- Bom... Como eu disse, ela era uma aristocrata inglesa e, portanto, morava na GrãBretanha com toda a pompa. Quando o partido do Hitler começou a crescer ela se tornou praticamente uma tiete. Tem, inclusive, fotos dela com a irmã fazendo o famoso "Sieg Heill". Por causa de toda essa admiração, ela foi até Munique para conhecer seu ídolo. E sabe qual foi o método que ela usou para conhecê-lo?

- Não faço a mínima ideia.

- Almoçava quase todos os dias no mesmo restaurante que ele costumava frequentar.

- Deu certo?

- Deu sim. Com o passar do tempo o Hitler chamou-a para sua mesa, bateram um papo e desde então se tornaram grandes amigos.

- Amigos?

- É, ao que tudo indica, só amigos. 
- Que loucura. E que fim teve essa moça? Parece que ela não devia ser uma simples admiradora das ideias do Hitler. Devia estar interessada também em outra coisa...

- Se matou.

- Por quê? - perguntou o sambista, embasbacado.

- Ela achava que o nazismo era a solução perfeita tanto para a Alemanha quanto para a Inglaterra. Quando houve a declaração de guerra entre os dois países, ela não aguentou a contradição e se suicidou.

- Nossa! Bem que você disse que era um período de loucos...

- Pois é. E, falando em loucos, você conhece o Himmler?

-Não. Quem é?

- Era o chefe do comando militar e da polícia nazista. Foi ele o grande responsável pelas matanças. Segundo historiadores, foi ele, inclusive, que colocou as mulheres e as crianças na lista de pessoas a serem eliminadas. Vou dar um exemplo da crueldade desse cara. Havia uma cidade da Ucrânia que tinha sido dominada pelos alemães por um tempo razoável e até a chegada dele nenhuma criança ou mulher judias que moravam lá tinham sido assassinadas. Depois que o Himmler chegou, o exército matou TODOS os judeus que ali viviam em quinze dias.

- Que filho da puta! - arrematou o sambista, batendo o copo no balcão e se dirigiu ao outro rapaz que bebia, mas não interferia na conversa. - E você, rapaz? Você não fala nada?!

- Prefiro não me meter em controvérsias - respondeu secamente.

- Controvérsias? Mas não tem nada de controvérsia, rapaz. O nosso amigo aqui só está contando histórias.

O outro se manteve impassível e retrucou calmamente:

- É, mas eu prefiro não me intrometer. Continuem, que estou apreciando.

- Cada louco... - comentou o sambista e retomou o diálogo com o historiador: - Mas diga lá. E esse diabo também tinha alguém que o amasse?

- Tinha. Na verdade o safado tinha duas famílias. Uma era a oficial e a outra era escondida, pois surgiu de um caso que ele teve com a secretária.

- Mais nova também?

- É. Também uns vinte anos.

- Cacete!

- Mas calma, que eu ainda não acabei de contar as loucuras desse sujeito doente.

- Manda vê. 
- Dizem que ele tinha uma teoria de que as mulheres perseguidas na Inquisição faziam parte do povo germânico. E realmente num período que inclui essa época os registros sobre o povo germânico são quase nulos. Por causa dessa suspeita, o Himmler era um aficionado por bruxas e bruxaria. Pesquisava e mandava funcionários pesquisarem sobre o tema e deixou um grande arquivo sobre o assunto. Com essas ideias na cabeça, aliás, usou um monte de referências de bruxaria para criar a simbologia do exército e da polícia. Um deles lembra o símbolo do BOPE... E você não sabe da maior! Por causa dessa teoria, dizem que ele chegou a propor para o Hitler que, além dos judeus, eles deveriam exterminar todos os cristãos, pois esses haviam perseguido os alemães. É claro que o Hitler não acatou.

Nesse momento o sambista não se aguentou e soltou uma gargalhada que lhe tirou o fôlego. Depois interveio:

- Meu Deus! Ainda bem que o Hitler não acatou. Já pensou? Não é possível! O cara queria matar todo o mundo!

- Pois é. Dá até para dizer que nesse momento o Hitler foi razoável.

- Hahahahahaha... Se foi...

- Deixa, então, eu contar uma última. Você nunca ouviu falar do marechal Erwin Johannes Eugen Rommel, mas conhecido como Raposa do Deserto?

- Benza Deus! O nome eu não conheço não, mas o apelido é familiar.

- Você já deve ter ouvido falar dele. Ele foi um dos mais importantes militares do exército alemão. Tinha muito jeito com discurso e com a propagada e, por isso, se tornou um dos favoritos do Hitler.

- E qual é a história desse noia?

- Ele era basicamente uma farsa. A única coisa que ele tinha de diferente em relação aos outros militares é que ele não tinha medo de nada. Por mais que parecesse impossível vencer o inimigo, mandava os soldados adiante. A batalha que o tornou famoso foi na África e foi mais ou menos assim... Ele chegou com seus soldados e, sem saber que havia um forte esquema de defesa do exército inglês e sem planejamento, avançou. Nessa brincadeira morreram mais de mil soldados à toa. Por puro teste. Teve um general que disse algo como "Rommel é um matador em pessoa, mas de estratégia nenhum sinal". E você acredita que o desgraçado acabou ganhando essa guerra e por causa dela ficou tão famoso?

- Acredito - disse o sambista, enfaticamente.

- Depois disso, as coisas não deram tão certo. Ele acabou sendo derrotado e acabou percebendo que a Alemanha estava se excedendo. Então, enquanto o mito da Raposa do Deserto ainda se mantinha, ele declarou várias vezes para o Hitler que o projeto expansionista 
deveria parar, porque traria resultados catastróficos. É óbvio que o Führer ficava puto com essas ideias e mandava que ele não revelasse suas opiniões a ninguém. No final das contas, o general preferido dele chegou até a planejar um atentado, que acabou não dando certo.

- Que loucura.

- Põe loucura nisso! Mas eu já falei demais. Agora é a sua vez.

- Ah, mas eu não tenho histórias tão interessantes quanto as suas.

- Você não toca à noite? Deve ter muitas histórias para contar.

- É. Eu toco sim, mas nesse momento não vem nada na cabeça.

Os três silenciaram. Bebiam sua cerveja com cadência. O barulho do tilintar de vidro e da água surrando a pia passou a dominar o ambiente. Lá fora o sol já brilhava forte, prometendo um dia muito quente. Dois pássaros se revezavam para bicar uma pequena poça d'água que diminuía na beira da calçada. Na rua Alberto Seabra não passava um carro sequer.

- Você conhece o Cartola, né? - perguntou o sambista de repente.

- Claro, claro - respondeu o historiador.

- Você sabe alguma coisa da história dele?

- Não.

- O Cartola era completamente xarope. Vivia fazendo uns bicos e cantava seus sambas num lugar ou outro, mas não construiu, aliás, acho que porque nem dava, uma carreira profissional. Um dia ele sumiu...

- Como assim sumiu?

- Simplesmente sumiu. Desapareceu de casa, desapareceu dos lugares que ele costumava frequentar e ninguém sabia onde ele tinha se metido. Passou um tempo um cara encontrou ele numa rua qualquer, trabalhando como flanelinha.

- E o que tinha acontecido com ele?

- Nada. Deu a louca e ele resolveu sumir. Daí esse cara que encontrou com ele levou-o de volta para perto dos conhecidos. Depois disso, fez a cabeça do Cartola, fechou com um estúdio e deu um jeito de ele gravar alguns sambas. São essas, praticamente, as únicas gravações que a gente tem. Se não fosse esse cara, ninguém ia conhecer nenhuma canção do Cartola, ainda mais se ele continuasse sumido.

- Caramba. Essa eu não conhecia...

- O Nelson Cavaquinho você conhece também, né?

- Claro!

- E nosso amigo lá? 
O sambista se referia àquele terceiro colega, o que estava ao lado do historiador e não falava quase nada. Não sei se por não entender ou por fingir não estar entendendo, ele não respondeu. Continuou com a expressão de quem presta meia atenção ao assunto, voltando os olhos ora para os contadores de história, ora para o nada.

- Deixa para lá... - conformou-se o sambista. - Você sabia que o Nelson Cavaquinho era policial?

- Policial?! Não. Não sabia, não.

- Pois é. Ele era policial e era policial à paisana. Só que, se você o conhece, já deve ter imaginado, ele saía atrás de bandido, mas sempre encontrava antes uma garrafa. Aí, pronto: sentava no bar e passava ali todo o expediente.

$\mathrm{O}$ historiador riu.

- Um dia ele tomou sua cota, pegou suas coisas, saiu do bar e: cadê o cavalo?

- Cavalo?!!!

- É. Ele trabalhava a cavalo.

- Puta merda! Mas como é que ele não ficou paraplégico?

- É. Isso aí é um milagre mesmo. Vai ver ele nunca subia no cavalo ou só subia quando estava sóbrio... De qualquer maneira, nesse dia aí ele foi atrás do bicho que ele havia prendido por perto e nada. Procurou, procurou, procurou. Nada. Foi até a central de polícia perguntar o que ele podia fazer e responderam: "seu Nelson, o negócio é muito simples: acha o cavalo ou paga". Imagina o desespero do homem... Resumindo a história, ele não achou o animal de jeito nenhum e, por isso, vendeu uma música que tinha feito com o Cartola para um outro sambista.

- Vendeu como? Os direitos?

- Que direitos, que nada... Vendeu para o tal do sambista dizer que a canção era dele. Isso era muito comum na época.

- Que sacanagem! Mas e o Cartola?

- Ah, depois que soube disso, nunca mais compôs nada com o Nelson.

- Sacanagem.

- É. O Nelson Cavaquinho não devia ser lá muito gente boa. Imagina ele como policial, bêbado... Depois procura no Youtube. Tem um documentário em que ele aparece enfiando bebida na goela de uns pintinhos e de uma criança.

- Ave. Que doente.

- Pois é. A bebida acaba com o homem.

Com essa deixa, tomaram mais um gole. 
- Tenho mais uma - avisou o sambista.

- Oba! Manda! - retrucou o historiador, animado.

- Você já ouviu falar no Zé Barbeiro?

- Zé Barbeiro? Não. Quem é?

- É um músico. Toca violão. Aliás, toca e compõe pra caralho!

- Legal! Vou procurar conhecer.

- Então... A gente toca junto toda quinta-feira. O cara é uma figura. Quando a cantora desafina ou inventa uma firula que ele não gosta, ele barbariza no violão: dá umas puta mãozadas e toca um monte de acorde dissonante. Às vezes ele também faz isso porque algum músico errou ou inventou novidade.

- E ninguém percebe?

- Você acha? O pessoal quer beber e dançar... Quem percebe, na verdade, percebe sempre e gosta, que eu sei. Tem um ou dois que vão sempre no bar que eu acho que ficam até esperando os protestos sonoros do Zé Barbeiro.

- Deve ser engraçado. Você não se incomoda?

-Eu? Não... Também fico esperando.

Os dois caíram na gargalhada. O sambista continuou:

- Outro dia chegaram duas francesas no bar. A cantora já tinha ido embora e a gente só estava tocando chorinho. Quando deu o intervalo, as duas chegaram no Zé Babeiro e pediram para cantar cada uma uma música. Para minha surpresa, ele aceitou e não deu nem sinal de contrariedade. Sentamos, tocamos e as duas cantaram.

- E ele barbarizou no violão?

- Não. Tocou tudo certinho.

- E elas cantavam bem?

- Nada de mais, mas eram afinadas. Sei que passaram alguns dias lá estavam elas de novo no bar. Antes de a gente começar, uma delas chegou para o Zé Barbeiro e perguntou se tinha cantado bem. Ele respondeu: "Sim. Você cantou muito bem. Não tenha dúvida". Deu uma pausa e completou: "só aquela sua amiga que tem uma voz que não dá para engolir". Claro que isso a deixou satisfeitíssima. Algumas horas depois, a amiga é que veio fazer a mesma pergunta. Sabe o que ele respondeu? "Sim. Você cantou muito bem. Não tenha dúvida". Deu uma pausa e completou: “só aquela sua amiga que tem uma voz que não dá para engolir".

Os dois caíram na gargalhada. O sambista tinha terminado sua sequência com uma ótima história. Pediram outra cerveja e, de quebra, uma Seleta. Brindaram ao "grande e 
imortal Zé Barbeiro"! Depois disso ficaram em silêncio novamente. E esperaram... O quê? Exatamente: era vez do terceiro colega se manifestar.

- Vai lá, rapaz. É a sua vez. Conta sua história - disse o sambista para ele.

Com ar misterioso e arrogante o outro respondeu:

- Prefiro ficar de fora.

- Meu amigo tem razão. Cada um de nós contou algumas histórias... Você não estava ouvindo? - intrometeu-se o historiador.

- Sim, estava.

- E não se distraiu?

- Sim, me distraí.

- Então é justo que você nos conte as suas.

- Eu não quero entrar em controvérsias.

- Mas não vai ter controvérsias! - continuou o historiador. - Pode ficar tranquilo.

Conta aí suas histórias.

- Na verdade é só uma. Mas eu prefiro não contar.

- Por quê? Conta. Você não tem nada a perder.

Aquele homem estranho respirou fundo, deitou os olhos sobre a chapa, refletindo sobre a proposição, e finalmente concordou:

- Tudo bem. Eu vou contar. Mas já aviso que ninguém pode me interromper.

- Combinado. Você não será interrompido. Fique tranquilo.

- Ok - e começou. - Eu venho do sul, de uma cidade muito pequena. Diferentemente daqui, lá tem muito verde. Lá a fauna é belíssima e corre um límpido rio que enfeita e canta por toda a região. Lá não se ouve o barulho de carros, de construção ou reformas, de aviões... Não existe violência nem trânsito. Lá eu nasci e lá haviam se instalado meus ancestrais alemães.

- Mas você falou que é do Rio Grande do Sul? Engraçado. Você não tem sotaque nenhum - comentou o sambista.

- Bem. Então não vou contar mais minha história. Eu falei que não queria controvérsia.

- Puta merda! Lá vem ele com essa porra de "controvérsia" de novo!

- Calma, meu amigo, calma - interveio o historiador. - Deixa nosso amigo contar a história dele. Não esquenta a cabeça com esses detalhes. Continue, rapaz. A gente promete que não vai interromper outra vez, não é? 
O sambista não teve outra opção senão concordar, sem esconder sua insatisfação. Reiniciou-se o relato:

- Se for assim, prosseguirei. Aviso que foi a primeira e última interrupção. $\mathrm{Na}$ segunda, vou-me embora.

Como estava dizendo, sempre morei nessa cidade e de lá era toda a minha família. Vivíamos com um pequeno comércio. Dominando desde o processo de colheita até a confecção do produto final, distribuíamos roupas para algumas lojas da região e tínhamos uma própria na minha cidade. Tudo era comedido, porque não precisávamos enriquecer. Nossa vida pacata não exigia muito dinheiro e já ganhávamos mais do que o suficiente para a sobrevivência.

Até eu conhecer a Margarete.

$\mathrm{Na}$ verdade eu já a conhecia, pois, como a cidade era muito pequena, conhecer a gente conhece todo mundo. O que acontece é que a Margarete cresceu. Ela era uma menina sem graça e insossa, mas, de repente, quando chegaram os dezesseis anos, seus olhos ganharam luz, suas pernas se alongaram, seu corpo fino e frágil ganhou um volume firme e irresistível. Sem saber que essa mudança toda havia se operado, ela ainda andava com suas roupas de criança, deixando à mostra as curvas e a violência da carne com as quais só podia rivalizar a beleza dos montes e do rio que davam vida a nossa terra. Sentia-me como se estivesse diante de uma assombração, quando lhe dava "bom dia", evitando olhar muito demoradamente para aquela pele branca e abismal e para aqueles lábios vermelhos que sangravam sem fim.

Dezesseis anos pode parecer pouco para vocês, mas no interior do sul é normal um relacionamento começar nessa idade. Até mesmo porque, em geral, nem o homem nem a mulher poderão ter outro. Por isso, logo comecei a cortejá-la e um ano depois estávamos casados. Mal sabia eu o inferno no qual me metia.

Tudo começou com a maldita mania por cães. Margarete adorava cães. Amava cães. Precisava de cães. Há anos eu morava na mesma casa, que ficava bem perto do rio e tinha a localização perfeita para eu tratar dos negócios da família. No entanto, por amor, comprei outra com um terreno maior e coloquei ali nada mais, nada menos do que quinze cachorros de diversas raças. Essa nova casa foi toda mobiliada ao gosto da minha mulher, que passava manhã, tarde e noite cuidando dos seus animais. De vez em quando sobrava tempo para nós jantarmos juntos...

Outra mania de Margarete era comprar: vestidos e joias. E olha que isso não fazia sentido nenhum na nossa realidade. Não só porque eu era dono de uma confecção... Onde ela iria com um vestido da Chanel e um colar da H. Stern?! Na igreja da pracinha central?! Lavar 
roupa na beira do rio?! É claro que não. Por isso ela ia enchendo os armários de joias e vestidos que ela nunca usaria. Até hoje não sei de onde ela tirou inspiração para esse vício medíocre. Deve ter sido dessas novelas que ela não podia deixar de assistir... E ai se eu não comprasse alguma coisa que ela queria. Era chantagem, era choro, era o que quer que fosse que arrebatasse meu coração apaixonado.

Lembram que eu disse que a loja e a produção eram pequenas? Tive que aumentá-las para sustentar as manias da minha mulher. Estudei melhor o mercado, contratei consultores, investi em funcionários e em tecnologia e expandi assustadoramente o negócio. Hoje a empresa da minha família tem unidades até aqui em São Paulo. Nunca me estressei tanto. Dinheiro só traz estresse. Surgiram tantas coisas com que precisava me preocupar que tinha até inveja dos funcionários que colhiam algodão das oito da manhã às três da tarde. Se um dos telefones (eu necessitava de mais de um) tocava no sábado de madrugada, tinha que atender e resolver o problema que fosse.

O que eu não sabia é que, além dos cachorros do meu terreno, havia outros com os quais aquela pequena cadela também se divertia. Margarete tinha feito uma fila de amantes e, por estarmos numa cidade pequena, só eu não sabia disso, mas logo descobri.

O normal seria eu matar cada um dos sujeitos que tinham me botado chifre, mas achei essa vingança muito óbvia, muito simplória. Então, depois de ter me informado sobre tudo tintim por tintim, fiquei quieto. Continuei tratando minha mulher como se nada tivesse acontecido, enquanto ia planejando a desforra.

Passou um mês exatamente e tudo estava decidido.

Num dia bem bonito disse a ela que tinha uma surpresa e que era para ela passar na casa de sua mãe e voltar dali a umas quatro horas para encontrar o que eu tinha preparado. Margarete nem desconfiou e obedeceu. Eu já tinha preparado tudo. Peguei as cordas que havia guardado no armazém e enforquei cada um dos cachorros. Deixei-os pendurados nas árvores que embelezavam o terreno de nossa casa. Catei as latas de querosene que havia comprado e espalhei tudo pela casa, com especial atenção aos vestidos e armários.

Eu disse que tinha pendurado cada um dos cachorros. Mas não foi exatamente isso. O favorito de Margarete, um labrador enorme, não teve o mesmo destino. Antes de tê-lo matado com veneno, fiz ele engolir a primeira e mais amada joia daquela vadia: um anel que era de sua tataravó, uma relíquia de família. Deitei-o sobre nossa churrasqueira junto com um facão e um recado: "se você quiser o anel de sua tataravó, vai ter que abrir seu amiguinho".

Ateei fogo à minha casa, fui embora da cidade e nunca mais voltei.

- Que coisa horrorosa! Isso aconteceu de verdade?! - não se conteve o historiador.

Mas quando ele e o sambista voltaram a si, o narrador tinha descido a rua. 